\title{
HIV Protease Inhibitors Do Not Cause the Accumulation of Prelamin A in PBMCs from Patients Receiving First Line Therapy: The ANRS EP45 "Aging" Study
}

\author{
Sophie Perrin ${ }^{1,2}$, Jonathan Cremer ${ }^{1,2 x}$, Olivia Faucher ${ }^{3}$, Jacques Reynes ${ }^{4}$, Pierre Dellamonica ${ }^{5}$, \\ Joëlle Micallef ${ }^{6}$, Caroline Solas ${ }^{7,8}$, Bruno Lacarelle ${ }^{7,8}$, Charlotte Stretti ${ }^{1,2}$, Elise Kaspi ${ }^{1,2}$, \\ Andrée Robaglia-Schlupp ${ }^{1,2}$, Corine Nicolino-Brunet Catherine Tamalet ${ }^{11}$, Nicolas Lévy ${ }^{1,12}$, \\ Isabelle Poizot-Martin ${ }^{4}$, Pierre Cau ${ }^{1,2}$, Patrice Roll ${ }^{1,2 *}$
}

1 Inserm UMR_S 910, Aix-Marseille Université, Marseille, France, 2 Laboratoire de Biologie Cellulaire, Centre Hospitalier Universitaire (CHU) La Timone Assistance Publique des Hôpitaux de Marseille (APHM), Marseille, France, 3 Service d'Immuno-Hématologie Clinique, Centre Hospitalier Universitaire (CHU) Sainte Marguerite Assistance Publique des Hôpitaux de Marseille (APHM), Marseille, France, 4 Département des Maladies Infectieuses et Tropicales, Centre Hospitalier Régional et Universitaire (CHRU) Gui-de-Chauliac, Montpellier, France, 5 Service d'Infectiologie, Centre Hospitalier Universitaire (CHU) L'Archet 1, Sophia-Antipolis Université, Nice, France, 6 Centre d'Investigation Clinique - Unité de Pharmacologie Clinique et d'Evaluations Thérapeutiques (CIC-UPCET), Centre Hospitalier Universitaire (CHU) La Timone Assistance Publique des Hôpitaux de Marseille (APHM), Marseille, France, 7 Laboratoire de Pharmacocinétique et de Toxicologie, Centre Hospitalier Universitaire (CHU) La Timone Assistance Publique des Hôpitaux de Marseille (APHM), Marseille, France, 8 Inserm UMR_S 911, Aix-Marseille Université, Marseille, France, 9 Laboratoire d'Hématologie, Centre Hospitalier Universitaire (CHU) La Conception Assistance Publique des Hôpitaux de Marseille (APHM), Marseille, France, 10 Fédération de Microbiologie Clinique, Centre Hospitalier Universitaire (CHU) La Timone Assistance Publique Hôpitaux de Marseille (APHM), Marseille, France, 11 CNRS (Centre Natonal de la Recherche Scientifique) IRD (Institut de Recherche pour le development) UM 63, Aix-Marseille Université, Marseille, France, 12 Laboratoire de Génetique Moléculaire, Centre Hospitalier Universitaire (CHU) La Timone Assistance Publique des Hôpitaux de Marseille (APHM), Marseille, France

\begin{abstract}
Background: The ANRS EP45 "Aging" study investigates the cellular mechanisms involved in the accelerated aging of HIV-1 infected and treated patients. The present report focuses on lamin A processing, a pathway known to be altered in systemic genetic progeroid syndromes.

Methods: 35 HIV-1 infected patients being treated with first line antiretroviral therapy (ART, mean duration at inclusion: $2.7 \pm 1.3$ years) containing boosted protease inhibitors ( $\mathrm{Pl} / \mathrm{r}$ ) (comprising lopinavir/ritonavir in $65 \%$ of patients) were recruited together with 49 seronegative age- and sex-matched control subjects (http://clinicaltrials.gov/, NCT01038999). In more than $88 \%$ of patients, the viral load was $<40$ copies $/ \mathrm{ml}$ and the CD4+ cell count was $>500 / \mathrm{mm}^{3}$. Prelamin A processing in peripheral blood mononuclear cells (PBMCs) from patients and controls was analysed by western blotting at inclusion. PBMCs from patients were also investigated at 12 and 24 months after enrolment in the study. PBMCs from healthy controls were also incubated with boosted lopinavir in culture medium containing various concentrations of proteins (4 to $80 \mathrm{~g} / \mathrm{L})$.
\end{abstract}

Results: Lamin A precursor was not observed in cohort patient PBMC regardless of the $\mathrm{Pl} / \mathrm{r}$ used, the dose and the plasma concentration. Prelamin A was detected in PBMC incubated in culture medium containing a low protein concentration (4 g/ $\mathrm{L})$ but not in plasma $(60-80 \mathrm{~g} / \mathrm{L})$ or in medium supplemented with BSA $(40 \mathrm{~g} / \mathrm{L})$, both of which contain a high protein concentration.

Conclusions: Prelamin A processing abnormalities were not observed in PBMCs from patients under the $\mathrm{PI} / \mathrm{r}$ first line regimen. Therefore, $\mathrm{Pl} / \mathrm{r}$ do not appear to contribute to lamin A-related aging in PBMCs. In cultured PBMCs from healthy donors, prelamin A processing abnormalities were only observed when the protein concentration in the culture medium was low, thus increasing the amount of PI available to enter cells. ClinicalTrials.gov NCT01038999 http://clinicaltrials.gov/ ct2/show/NCT01038999.

Citation: Perrin S, Cremer J, Faucher O, Reynes J, Dellamonica P, et al. (2012) HIV Protease Inhibitors Do Not Cause the Accumulation of Prelamin A in PBMCs from Patients Receiving First Line Therapy: The ANRS EP45 “Aging" Study. PLoS ONE 7(12): e53035. doi:10.1371/journal.pone.0053035

Editor: Clive M. Gray, University of Cape Town, South Africa

Received August 8, 2012; Accepted November 22, 2012; Published December 28, 2012

Copyright: (C) 2012 Perrin et al. This is an open-access article distributed under the terms of the Creative Commons Attribution License, which permits unrestricted use, distribution, and reproduction in any medium, provided the original author and source are credited.

Funding: This work was supported by the French National Agency for Research on AIDS and Viral Hepatitis (ANRS, http://www.anrs.fr/) [ANRS EP45 "Aging" to PC]. SP was a recipient of a 3-year PhD grant from ANRS [ANRS EP45 "Aging" to PC] and an additional one-year PhD grant from Sidaction (http://www.sidaction. org/) [B/22-2-02032 to SP]. SP received a 3-month transition grant from ADEREM (Biological and medical research supportive association for Marseille hospital centres, http://aderem.fr/index.htm). JC was a recipient of a grant from Sidaction [A/19-3-01487 to PC]. PC was a recipient of grants from GlaxoSmithKline and from Boehringer Mannheim. The funders had no role in study design, data collection and analysis, decision to publish, or preparation of the manuscript. 
Competing Interests: The authors have the following interests. PC was a recipient of grants from GlaxoSmithKline and from Boehringer Mannheim. There are no patents, products in development or marketed products to declare. This does not alter the authors' adherence to all the PLOS ONE policies on sharing data and materials, as detailed online in the guide for authors.

* E-mail: patrice.roll@univ-amu.fr

a Current address: KUL GHB CDG, Labo Klinische Immunologie, Leuven, Belgium

\section{Introduction}

The A-type lamins are type $\mathrm{V}$ intermediate filaments that are key components of the nuclear matrix. Lamins $\mathrm{A}$ and $\mathrm{C}$, which are obtained by alternative splicing of the $L M N A$ gene, are the predominant A-type lamins [1]. Lamin $\mathrm{C}$ is produced directly as a mature protein, while lamins A undergo several posttranslational modifications $[2,3,4]$. Mature proteins are obtained from their precursors through 4 posttranslational steps. The cysteine residue in the C-terminal CaaX box is farnesylated in the first step [5], following which the aaX residues are removed by the endopeptidases, FACE1/ZMPSTE24 (farnesyl converting enzyme 1/zinc metalloprotease related to yeast ste24p) and/or FACE2/RCE1 (farnesyl converting enzyme 2/Ras-converting enzyme 1) [6]. The cysteine is subsequently carboxymethylated by ICMT (isoprenylcysteine carboxyl methyltransferase) [6]. Following this step, the last 15 C-terminal amino acids of prelamin $\mathrm{A}$ are cleaved by FACE1/ZMPSTE24 to release a mature unfarnesylated soluble protein present in both the lamina and in the rest of the nucleoplasm $[7,8]$.

In the lamina, lamins interact with several nuclear envelope or nucleoplasmic partners $[2,3,4,9]$. In addition to their role in determining nuclear shape and size, A-type lamins are believed to form a scaffold that supports a wide variety of mechanisms, including chromatin organization, gene transcription, DNA synthesis and damage repair, cell proliferation and differentiation $[2,3,4,9]$.

Increasing numbers of mutations in LMNA, ZMPSTE24 or genes encoding lamin partners have been associated with tissuerestricted or systemic disorders collectively termed "laminopathies". Indeed, pathologies of striated muscle $[10,11,12]$, peripheral nerve [13] and adipose tissue [14,15,16] have been reported. Systemic progeroid syndromes that mimic the clinical features of physiological aging have also been described. The HutchinsonGilford progeria syndrome (HGPS) $[13,17]$ occurs, in most cases, through the de novo dominant $L M N A$ p.G608G mutation, which results in the persistence of a truncated farnesylated prelamin $\mathrm{A}$ (lamin $\mathrm{A} \Delta 50$, also called progerin) [18]. At clinical levels, these abnormalities lead to severe growth retardation, skeletal alterations (osteolysis, osteoporosis), marked amyotrophy, lipodystrophy and atherosclerosis [18,19]. Restrictive dermopathy (RD), another systemic progeroid syndrome that is lethal during the perinatal period, is linked to mutations mainly in the ZMPSTE24 or $L M N A$ genes which also result in the persistence of farnesylated prelamin A [20,21]. Interestingly, low levels of lamin A $\Delta 50$ [22] and farnesylated prelamin A (resulting from the FACE1/ ZMPSTE24 defect) [23] are produced during physiological aging.

Both treated and untreated HIV (human immunodeficiency virus) infected patients exhibit clinical and biological disorders similar to those observed in genetic laminopathies. Indeed, lipodystrophy, cardiovascular disease, sarcopenia and metabolic abnormalities have been reported in addition to bone and kidney complications $[24,25]$. Lipodystrophy has been frequently reported as a side effect of treatment with PIs (protease inhibitors) or with NRTIs (nucleoside reverse transcriptase inhibitors) [26]. Some of these age-related disorders were found to be more common in
HIV infected and treated patients than in the general population [27], suggesting a modified time course of aging in HIV patients.

Alterations in lamins have previously been reported during viral infection (herpes simplex virus [28]; cytomegalovirus [29]). During HIV-1 infection, Vpr (viral protein r) induced a transient local disassembly of lamina that resulted in nucleoplasm herniations [30]. This mechanism is believed to allow the penetration of HIV preintegration complex into the nucleoplasm. Interestingly, similar but permanent herniations were found in HGPS or RD cells, and represent a classical feature of genetic laminopathies [20,21]. Besides the transient effect of HIV proteins, lamina alteration could also be due to treatment with boosted protease inhibitors (PI/r).

Indeed, in cultured cells, some PIs have been reported to inhibit FACE1/ZMPSTE24 [31,32] and induce the persistence of farnesylated prelamin A [31,32,33,34]. Reduction of the lamin A mRNA level has also been highlighted in adipose tissue from HIV infected and treated patients regardless of the clinical presence of lipodystrophy [35]. Prelamin A has been detected in adipose tissue from lipodystrophic HIV infected patients treated with first generation PIs (indinavir or nelfinavir) [36,37]. In spite of these observations, the role of lamin A in the aging of HIV infected and treated patients remains to be clarified.

The ANRS EP45 "Aging" study investigates the cellular mechanisms involved in aging in these patients. Functional and morphological parameters in mitochondria, organelles known to be involved in cellular aging, have already been explored in peripheral blood mononuclear cells (PBMCs) from our cohort [38]. The present study focused on prelamin A in PBMCs from 35 HIV-1 infected patients treated with first line antiretroviral therapy (ART) comprising 2NRTI+1PI/r. No prelamin A was detected at inclusion or up to two years after enrolment in the study, regardless of the $\mathrm{PI} / \mathrm{r}$ used, their dose or their plasma concentration. PI/r do not appear to contribute to lamin A-related aging in PBMCs. Moreover, we demonstrated that prelamin A could be detected in PBMCs incubated with $\mathrm{PI} / \mathrm{r}$, but only if the culture medium contained a low protein concentration, at least ten times less than in human plasma. Our results may explain the discrepancy between the detection of prelamin A in cultured cells and patient peripheral blood cells.

\section{Methods}

\section{ANRS EP45 Study \& Participant Characteristics}

The ANRS EP45 "Aging" study is a cross-sectional and longitudinal multicentric study (Marseille, Montpellier and Nice; France). The protocols for this trial is available as supporting information, see Protocol S1. Basic demographic, clinical, biological parameters and ART combinations are partially detailed in Tables S1 and S2 from [38].

Briefly, 179 participants were enrolled according their HIV-1 or ART status. Among them, $35 \mathrm{HIV}-1$ infected patients receiving first line ART comprising a 2NRTI and PI/r regimen for at least 12 months were recruited at inclusion (M0; Month 0). PIs were administered twice or once daily according clinician's prescription. Atazanavir was exclusively administered once daily. Lopinavir and amprenavir were administered twice daily in $90 \%$ and $80 \%$ of 
patients respectively. At inclusion, the mean treatment duration was 2.7 ( \pm 1.3$)$ years. The PI/r regimen contained lopinavir $(69 \%$ of patients), atazanavir (14\%) or fosamprenavir (14\%). Ritonavir was always used as a booster. None of the patients were treated with an ART regimen containing boosted darunavir. Forty-nine seronegative age- and sex-matched subjects were used as a control group. Patients were followed-up one (M12; month 12) and two years (M24; month 24) after inclusion (M0).

We report here the nuclear protein data measured at M0, M12 and M24.

\section{Ethics Statement}

The French Health Products Safety Agency Regulatory Authority (AFSSAPS, Agence Française de Sécurité Sanitaire des Produits de Santé) and Marseille Ethical Committee (Comité de Protection des Personne Sud Méditerranée I) approved the protocol. The study, registered on the ClinicalTrials.gov web site (Identifier: NGT01038999), was performed in accordance with the Declaration of Helsinki. All subjects gave written informed consent before participation.

\section{Blood Puncture}

Blood samples from patients under treatment were simultaneously collected in EDTA (for cellular analyses) and in heparinlithium (for PI/r plasma concentration assays).

\section{$\mathrm{Pl} / \mathrm{r}$ Plasma Concentration}

Lopinavir remained stable during our sample processing (data not shown) in accordance with the well-known stability of PIs $[39,40,41,42,43]$. Plasma separation was performed on receipt of the blood tubes, following which the plasma was stored at $-20^{\circ} \mathrm{C}$ prior to analysis. The concentration of $\mathrm{PI} / \mathrm{r}$ in plasma was quantified by analysing plasma recovered from blood collected in lithium heparinized tubes (BD Vacutainer) using a specific and sensitive validated liquid chromatography-tandem mass spectrometry (LC-MS/MS) method [44].

\section{PBMC Isolation from Patients}

To standardize sample processing despite shipping delays between HIV Clinical Units (Montpellier, Nice and Marseille) and the Cell Biology Laboratory (Marseille), blood collected in EDTA Vacutainer tubes (Becton Dickinson) was rotated overnight at room temperature before PBMCs isolation using Ficoll ${ }^{\circledR}$. Cells viability was maintained at $>97 \%$ (data not shown). PBMCs were isolated by Ficoll ${ }^{\circledR}$ gradient centrifugation (UNI-SEP MAXI+, Novamed) according to the manufacturer's instructions. Leucocyte formulae were calculated in May-Grünwald-Giemsa-stained Cytospin ${ }^{\circledR}$ samples. Directly after PBMC isolation, residual red blood cells, if any, were hypotonically lysed in $100 \mu \mathrm{M}$ EDTA, $150 \mathrm{mM} \mathrm{NH} \mathrm{NH}_{4} \mathrm{Cl}, 1 \mathrm{mM} \mathrm{KHCO}_{3}, \mathrm{pH}$ 7.4. Cells were stored immediately at $-80^{\circ} \mathrm{C}$.

\section{Reagents}

Lopinavir was kindly provided by Abbot to the Department of Pharmacokinetics and Toxicology (APHM Timone Hospital, Marseille, France). A $20 \mathrm{mM}$ stock solution was prepared in DMSO.

Zoledronic acid (Zometa ${ }^{\circledR}$, Novartis) and sodium pravastatine (Phr.Eu quality, Hisun Pharmaceuticals) were used in combination (ZoPra). Stock solutions were $2.76 \mathrm{mM}$ for zoledronate (diluted in $\left.\mathrm{H}_{2} \mathrm{O}\right)$ and $8.96 \mathrm{mM}$ for pravastatine (diluted in PBS).

\section{Incubation of PBMCs from Healthy Donors with Lopinavir/r}

Freshly isolated PBMCs from healthy donors were incubated in RPMI (Life Technologies) containing 10\% FBS (foetal bovine serum; Life Technologies) and $2 \mathrm{mM} \mathrm{L-glutamine} \mathrm{(Life} \mathrm{Technol-}$ ogies) for 24 hours at $37^{\circ} \mathrm{C}$ in a humidified atmosphere containing $5 \% \mathrm{CO}_{2}$. PBMCs were treated with lopinavir (concentration range: 2, 20, 40 and $200 \mu \mathrm{M}$ ). PBMCs were also incubated with the same concentration of lopinavir in medium containing lopinavir at the same concentrations that was also supplemented with bovine serum albumin (BSA) up to $40 \mathrm{~g} / \mathrm{L}$ or plasma recovered during PBMCs isolation. PBMCs incubated with DMSO only ( $\leq 1 \%$ depending of the PI concentration used) were used as negative control cells. Experiments were performed at least in triplicate.

Cell viability was determined using $0.4 \%$ trypan blue (Lonza). At least 200 cells were counted per condition.

\section{Incubation of PBMCs from Healthy Donors with ZoPra}

The ZoPra combination blocks the farnesylation of prelamin A [45], thus preventing the cleavage of prelamin A by FACE1/ ZMPSTE24 to generate mature lamin A. In control conditions except during physiological aging [22,23], normal maturation of lamin A precludes the detection of its prelamin A precursor. Therefore, we used the ZoPra combination to block prelamin A processing in PBMCs such that prelamin A accumulated in the cells. PBMCs from healthy seronegative subjects were incubated in culture medium containing $60 \mu \mathrm{M}$ of ZoPra for $24 \mathrm{~h}$ at $37^{\circ} \mathrm{C}, 5 \%$ $\mathrm{CO}_{2}$. These cells were used as a positive control for the detection of prelamin A by western blotting (WB), immunofluorescence (IF) and flow cytometry analysis (Figure S1).

\section{Protein Extraction}

Total PBMC proteins were extracted in 2X Laemmli buffer (Tris base $\mathrm{pH} 6.8,6 \%$ SDS, $10 \% \quad \beta$-mercaptoethanol, $10 \%$ glycerol, 0,1 M dithiothreitol [34]).

\section{Western Blotting}

Protein lysates were separated on Nupage ${ }^{\circledR}$ Novex 8\% Bis-Tris precast gels (Life Technologies) and transferred to Immobilon-FL PVDF membranes (Millipore). Membranes were blocked for one hour in 1:2 diluted blocking buffer for near infrared fluorescent western blotting (Rockland). Blocked membranes were incubated with primary antibodies for one hour at room temperature (RT), following which they were washed and incubated with IR-Dye conjugated secondary antibodies for one hour at RT. Bound antibodies were detected and analysed on an Odyssey ${ }^{\circledR}$ V3.0 imaging system (LI-COR Biosciences) according to the manufacturer's instructions. Glyceraldehyde 3-phosphate dehydrogenase (GAPDH) was used as a total cellular protein loading control.

\section{Immunofluorescence}

Immunofluorescence staining of lamin A and prelamin A was performed in PBMC from 179 cohort participants at M0 according to a standard procedure, as described in Methods S1. Experiments were performed blinded with respect to subject status (treated HIV-1 patients or control subjects).

\section{Antibodies}

The following antibodies were used in this study: mouse monoclonal anti-lamin A/C (MAB3211, 1/200, Millipore), goat polyclonal anti-lamin A/C (sc6215, 1/200, Santa Cruz), rabbit polyclonal anti-lamin A/C (sc20681, 1/200, Santa Cruz), goat 
polyclonal anti-prelamin A (sc6214, 1/200, Santa Cruz), rabbit polyclonal anti-prelamin A (ANT0045, 1/100, Diatheva), mouse monoclonal anti-GAPDH (MAB374, 1/40,000, Millipore).

Secondary antibodies conjugated with IR-Dye 800CW or 680 were used according to the manufacturer's instructions (92632212，926-32214，926-32223，926-32224，1/5000，LI-COR ${ }^{\circledR}$ Biosciences).

\section{Statistical Analysis}

Statistical and box plot analyses were performed using GraphPad Prism 5.04 (GraphPad Software, Inc.). Cell viability was compared between conditions using the Mann-Whitney test. $p$ values of $<0.05$ were considered statistically significant. Box plots of the PI plasma concentration from patients displayed the median, min and max values.

\section{Results}

ANRS EP45 "Aging" Patients Exhibited Good Compliance to Treatments and Mainly Remained in the Common

\section{Drug Therapeutic Range}

The total plasma PI/r level, which includes both bound and unbound drug, was evaluated for each patient at each follow-up visit. Samples were drawn 10-12 hours post-dose (for twice daily administration) or 20-24 hours post-dose (for once daily administration) to obtain the trough concentration (Cmin). In some cases, samples were drawn at the maximal concentration (Cmax) (3-6 hours, 2-4 hours and 1-3 hours after drug intake for lopinavir, atazanavir and fosamprenavir, respectively).

The lopinavir median plasma concentrations were $8 \mu \mathrm{M}$ (range: $0-18.9)$ at $\mathrm{M} 0,11.8 \mu \mathrm{M}(5.9-19)$ at $\mathrm{M} 12$ and $7.4 \mu \mathrm{M}(0.8-18.1)$ at M24 (Figure 1A), which corresponded to Cmin or Cmax in 82$85 \%$ and $8-9 \%$ of cases, respectively. Of the lopinavir plasma samples from our patients, 70\% (M0), 69\% (M12) and 82\% (M24) of lopinavir plasma samples from our patients remained within the recommended therapeutic range (Cmin, 1.6-12.7 $\mu \mathrm{M}$; Cmax, 11.1-17.4 $\mu \mathrm{M})$. The corresponding ritonavir median plasma concentrations were $0.28 \mu \mathrm{M}$ (range: $0-1.8$ ) at $\mathrm{M} 0,0.33 \mu \mathrm{M}$ $(0.13-1.0)$ at M12 and $0.22 \mu \mathrm{M}(0.07-1.8)$ at M24 (Figure 1A).

The atazanavir median plasma concentrations were $1.9 \mu \mathrm{M}$ (range: $0.7-4.8)$ at $\mathrm{M} 0,0.9 \mu \mathrm{M}(0-4.3)$ at $\mathrm{M} 12$ and $0.8 \mu \mathrm{M}(0-1.4)$ at M24 (Figure 1A). 60-80\% of the patient samples were between Cmax (therapeutic range: $3.3-11.6 \mu \mathrm{M})$ and Cmin $(0.3-1.1 \mu \mathrm{M})$. The corresponding ritonavir median (range) plasma concentrations were $0.22 \mu \mathrm{M}(0.08-1.1)$ at $\mathrm{M} 0,0.11 \mu \mathrm{M}(0-1.0)$ at $\mathrm{M} 12$ and $0.22 \mu \mathrm{M}(0-0.63)$ at M24 (Figure 1A).

The amprenavir median plasma concentrations were $2.8 \mu \mathrm{M}$ (range: $0.7-4.2)$ at $\mathrm{M} 0,4 \mu \mathrm{M}(3.1-5)$ at $\mathrm{M} 12$ and $4.1 \mu \mathrm{M}(2.2-4.4)$ at M24 (data not shown). $67-80 \%$ of the patient samples were measured at Cmin (therapeutic range: 1.6-9.9 $\mu \mathrm{M}$; Cmax, 9.9$15.8 \mu \mathrm{M})$. The corresponding ritonavir median plasma concentrations were $0.14 \mu \mathrm{M}$ (range: $0-0.2)$ at $\mathrm{M} 0,0.16 \mu \mathrm{M}(0.14-0.18$ ) at M12 and $0.12 \mu \mathrm{M}(0.11-0.13)$ at M24 (data not shown).

\section{Prelamin A was Not Detected in PBMCs from Patients being Treated with the $2 \mathrm{NRTI}+1 \mathrm{PI} / \mathrm{r}$ Regimen}

No prelamin A was detected by immunofluorescence staining of PBMCs obtained from any of the cohort participants at M0 (data not shown).

In order to detect alterations in prelamin A processing, PBMCs from control subjects $(\mathrm{n}=11)$ and patients receiving the $2 \mathrm{NRTI}+1 \mathrm{PI} / \mathrm{r}$ regimen $(\mathrm{n}=35)$ were analysed by western blotting at M0 using a combination of antibodies specific to lamin $\mathrm{A} / \mathrm{C}$ and prelamin A. Patient PBMCs were also analysed at M12 and M24.

Prelamin A was not detected in PBMCs from any patients regardless of $\mathrm{PI} / \mathrm{r}$, posology or plasma concentration. Representative blots from patients receiving lopinavir or atazanavir are shown in Figure 1B. Three commercial antibodies raised against various epitopes in lamins $\mathrm{A}$ and $\mathrm{C}$ showed different sensitivities for prelamin A detection. In light of these results, samples from patients exhibiting the highest lopinavir plasma concentrations were analysed using these three antibodies (Figures S2A, S2C), as well as the most sensitive commercial prelamin A specific antibody available (Figure S2B), confirming the absence of prelamin A in PBMCs from PI/r treated patients (Figure S3).

\section{The Protein Concentration of PI Incubation Medium Influences the Effect of PIs on Prelamin A Processing in PBMC}

PBMCs from healthy donors incubated in plasma (total protein concentration: $60-80 \mathrm{~g} / \mathrm{L}$ ) for $24 \mathrm{~h}$ displayed a cell viability of $76 \% \pm 4.2$ (mean $\pm \mathrm{SD}$ ) (Figure 2A). No alterations were detected after lopinavir treatment regardless of the concentration of drug used. In contrast, the viability of PBMCs incubated for the same duration in RPMI culture medium supplemented with 10\% FBS (total protein concentration: $4 \mathrm{~g} / \mathrm{L}$ ) decreased significantly to $-11 \%$ for PBMCs incubated with $20 \mu \mathrm{M}$ lopinavir compared to untreated cells $(\mathrm{p}=0.002) ;-23 \%$ for PBMCs incubated with $40 \mu \mathrm{M}$ lopinavir compared to untreated cells $(\mathrm{p}=0.003)$; and $-12 \%$ for PBMC treated with $40 \mu \mathrm{M}$ compared to $20 \mu \mathrm{M}$ lopinavir $(p=0.001)$ (Figure 2A). Moreover, no loss of viability was apparent in cells incubated with 20 or $40 \mu \mathrm{M}$ lopinavir in BSA supplemented medium (final total protein concentration: $40 \mathrm{~g} / \mathrm{L}$ ). Interestingly, a slight viability decrease $(-12 \%, \mathrm{p}=0,07)$ was observed in cells treated with $200 \mu \mathrm{M}$ lopinavir compared to cells incubated with $20 \mu \mathrm{M}$ lopinavir (Figure 2A).

At the same time, no prelamin A was detected in PBMCs incubated in plasma regardless of the concentration of lopinavir used (Figure 2B). In contrast, prelamin A was identified in PBMC incubated in culture medium supplemented with 10\% FBS and lopinavir, with the ratios of prelamin $\mathrm{A} /$ (prelamin A+lamin A) being $18 \% \pm 0.7 \%($ mean $\pm \mathrm{SD}, \mathrm{n}=3)$ and $30 \% \pm 5.0 \%(\mathrm{n}=3)$ for $20 \mu \mathrm{M}$ or $40 \mu \mathrm{M}$ lopinavir, respectively (Figure $2 \mathrm{~B}$ ). After the addition of BSA to the culture medium (total protein concentration: $40 \mathrm{~g} / \mathrm{L}$ ), no prelamin A was observed in the presence of 20 or $40 \mu \mathrm{M}$ lopinavir. In BSA supplemented medium, prelamin A was only detected in cells treated with $200 \mu \mathrm{M}$ lopinavir (ratio: $30 \%$; Figure 2B). Interestingly, the presence of prelamin A seemed to be negatively correlated with cell viability.

\section{Discussion}

The aim of the ANRS EP45 "Aging" study is to investigate the cellular mechanisms involved in the accelerated aging of HIV-1 infected and treated patients. Previous studies demonstrated that in cultured cells, $\mathrm{PI} / \mathrm{r}$ induced alterations in prelamin A processing similar to those already reported in some genetic progeroid syndromes, such as progeria or restrictive dermopathy. Our hypothesis was that $\mathrm{PI} / \mathrm{r}$ could reproduce the molecular mechanism underlying these genetic diseases through the accumulation of farnesylated prelamin A, thus contributing to aging in HIV infected and treated patients. 
A

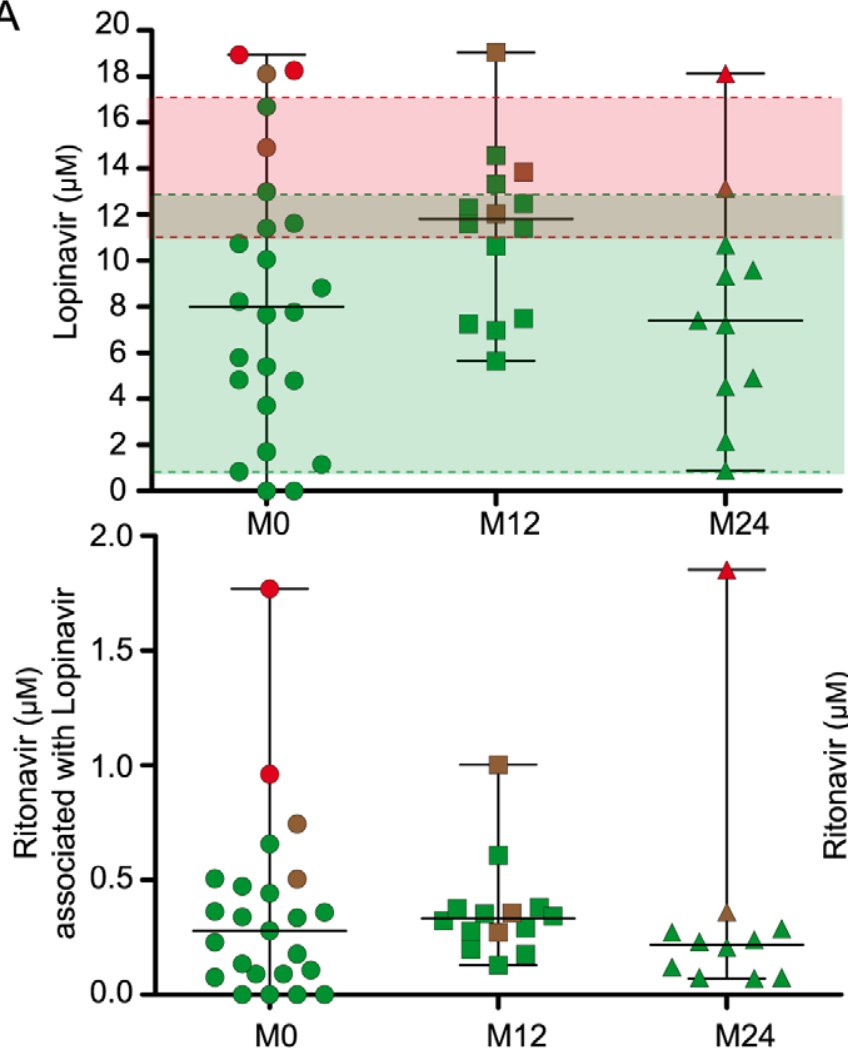

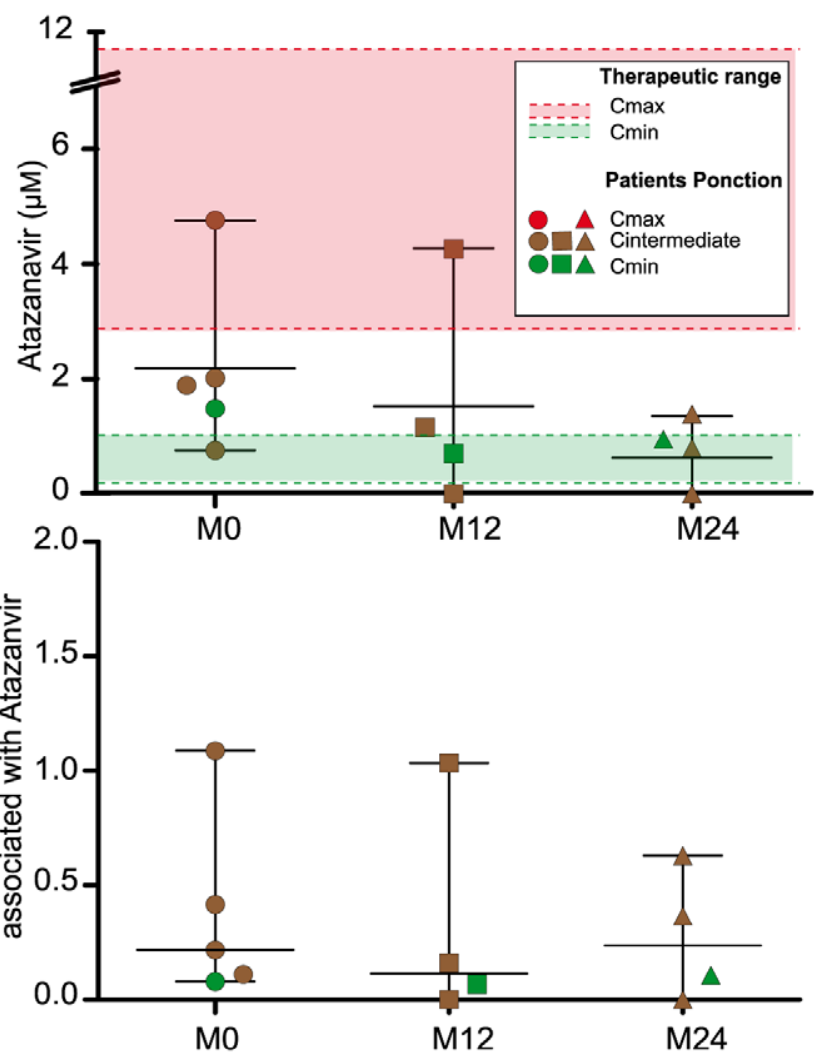

B

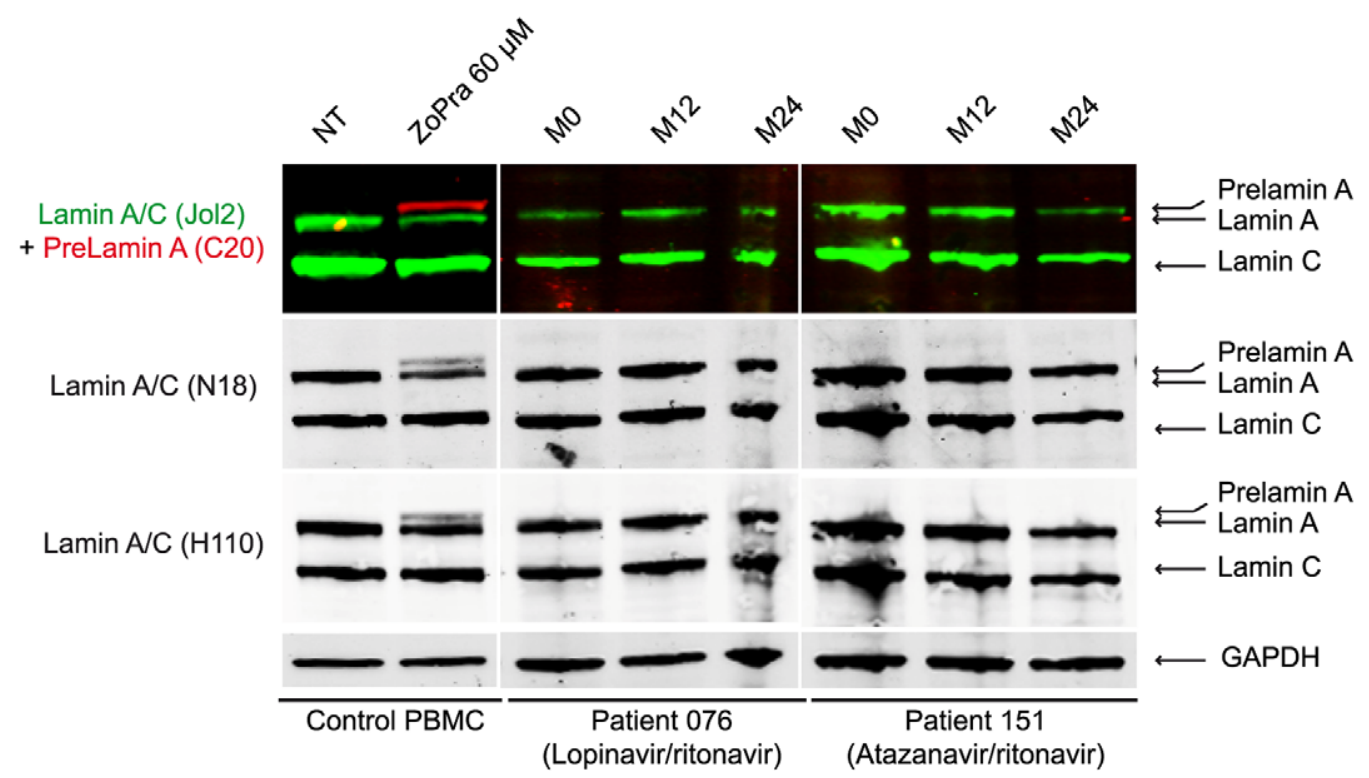

Figure 1. Lack of prelamin A in PBMCs from compliant patients receiving the $2 \mathrm{NRTI}+1 \mathrm{PI} / \mathbf{r}$ regimen. (A) Plasma concentrations of lopinavir, atazanavir and ritonavir from ANRS EP45 "Aging" patients reported at M0 (circles), M12 (square) and M24 (triangle). Colors indicate the durations between last drug uptake and venipuncture ( $\mathrm{Cmax}$, red; $\mathrm{Cmin}$, green, Cintermediate, brown) and PI therapeutic concentration range (Cmax, red; Cmin, green). The majority of patients receiving lopinavir treatment were assayed at $\mathrm{Cmin}$ and remained within the therapeutic range. Samples from patients being treated with the atazanavir regimen were mainly assayed at mid-dose. (B) Representative western blots of PBMCs from patients receiving lopinavir or atazanavir treatment using three different lamin A/C-specific antibodies and one prelamin A-specific antibody. No prelamin $A$ was detected in PBMCs from patients. Control PBMCs from healthy controls incubated with ZoPra were used as positive control cells. PI plasma concentrations in the patients shown: lopinavir $10.7 \mu \mathrm{M}(\mathrm{M} 0), 12.3 \mu \mathrm{M}$ (M12) and 9.3 $\mu \mathrm{M}$ (M24); atazanavir $1.5 \mu \mathrm{M}(\mathrm{M} 0), 0.7 \mu \mathrm{M}(\mathrm{M} 12)$ and $0 \mu \mathrm{M}(\mathrm{M} 24)$. doi:10.1371/journal.pone.0053035.g001 
A
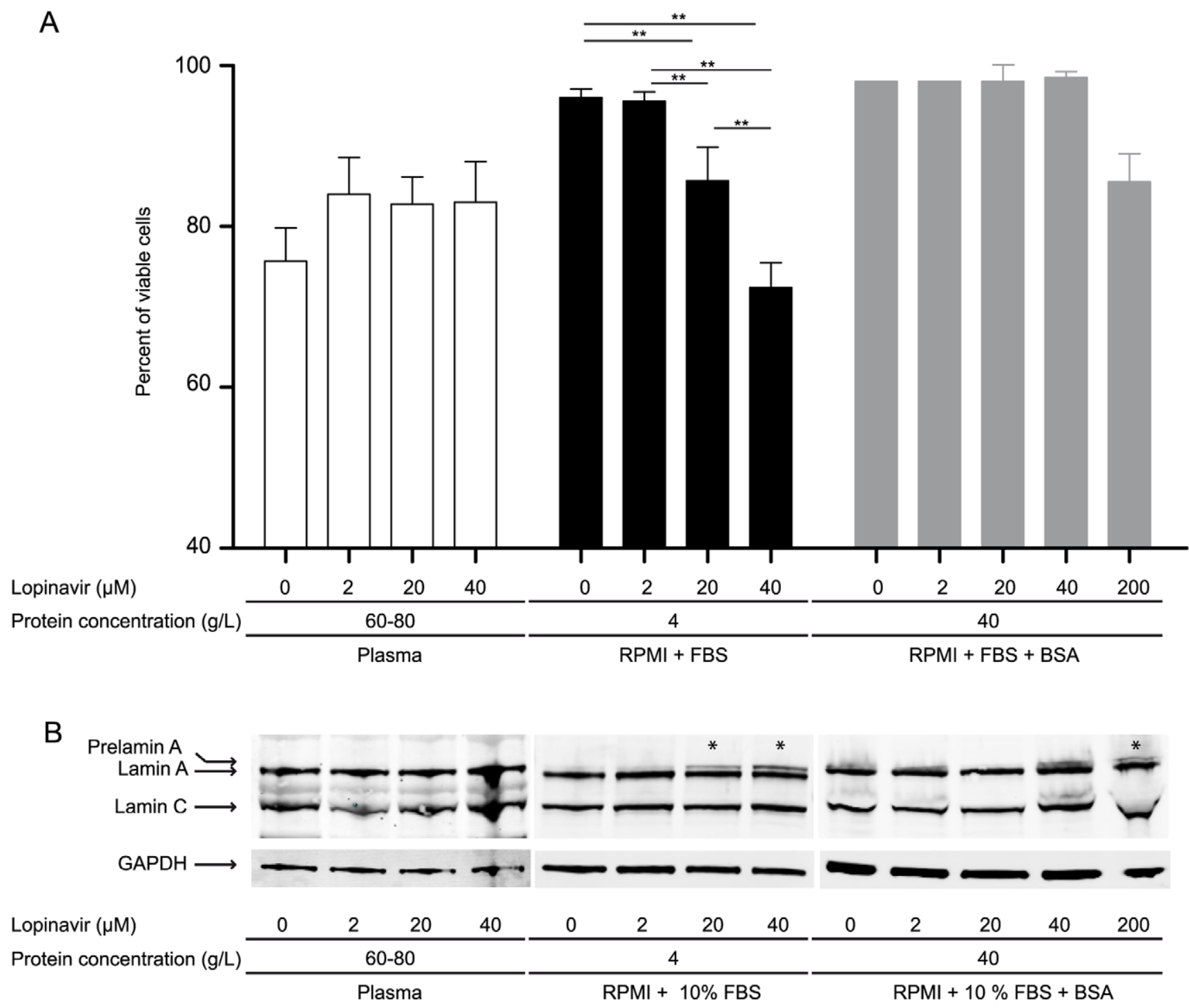

Figure 2. The protein concentration of PI incubation medium influences the effect of PI on prelamin A processing in PBMC. PBMC were incubated for 24 hours with increasing concentrations of lopinavir $(0,2,20,40,200 \mu \mathrm{M})$ diluted in plasma (total protein concentration: $60-80 \mathrm{~g} /$ $\mathrm{L}$ ), in RPMI culture medium supplemented with $10 \% \mathrm{FBS}$ and $2 \mathrm{mM} \mathrm{L-glutamine} \mathrm{(total} \mathrm{protein} \mathrm{concentration:} 4 \mathrm{~g} / \mathrm{L}$ ), or in the RPMI culture medium supplemented with BSA (total protein concentration: $40 \mathrm{~g} / \mathrm{L}$ ). (A) Percentage of viable cells in plasma (white), culture medium (black), and BSA supplemented culture medium (gray) (error bars $=S D, n \geq 3$, at least 200 cells counted in each experiment). ${ }^{* *} p<0.01$. No viability changes were observed when PBMC were incubated in plasma containing lopinavir. A decrease in cell viability was apparent when PBMC were incubated in culture medium containing $20 \mu \mathrm{M}$ or $40 \mu \mathrm{M} \mathrm{PI}$. Only a slight decrease in viability was observed in cells incubated in BSA supplemented culture medium containing $200 \mu \mathrm{M} \mathrm{PI}$. (B) Western blotting experiments. Both plasma and BSA supplemented culture medium containing 2 to $40 \mu \mathrm{M}$ lopinavir had no effect on prelamin A maturation in PBMC. Prelamin A (anti-lamin A/C H110) was detected ${ }^{*}$ ) in culture medium containing $20 \mu \mathrm{M}$ and $40 \mu \mathrm{M}$ lopinavir, and in BSA supplemented culture medium containing $200 \mu \mathrm{M}$ lopinavir. Fibroblasts were cultured in the presence or absence of either $20 \mu \mathrm{M}$ lopinavir (farnesylated prelamin A positive control) or $60 \mu \mathrm{M}$ ZoPra (unfarnesylated prelamin A positive control) for 72 hours. GAPDH was used as total cellular protein loading control. (A) Western blot comparing the three lamin A/C antibodies used (N18, sc6215; H110, sc20681; Jol2, MAB3211). All antibodies recognized both lamin A and lamin C. Different amounts of farnesylated prelamin A were detected by N18 and H110, as shown by the ratio of prelamin A reported to the total prelamin A+lamin A signal. In the same conditions, Jol2 did not detect prelamin A. (B) Western blot comparing the two prelamin A antibodies tested (sc6214, ANT0045). The sc6214 antibody exhibited a higher affinity for both farnesylated and unfarnesylated prelamin A than the ANT0045 antibody. (C) Prelamin A, lamin A and lamin C protein domains and antibody epitopes. Lamin A/C N18 (sc6215, green); lamin A/C H110 (sc20681, blue); lamin A/C Jol2 (MAB3211, purple); prelamin A sc6214 (pink); prelamin A ANT0045 (orange). doi:10.1371/journal.pone.0053035.g002

\section{Lopinavir Induced Prelamin A Accumulation in Cultured Cells}

Several publications have previously reported the induction of prelamin A accumulation after PI treatment of various cultured human cell types, including dermal fibroblasts [31,32], differen- tiating adipocytes [36,46], HCAEGs (human coronary artery endothelial cells, [34]) and osteosarcoma Saos-2 cells [33].

In these studies, the duration of PI treatment varied from $48 \mathrm{~h}$ up to 30 days. Interestingly, not all PI molecules seemed to induce this phenomenon. Indeed, after incubation for at least 10 days, indinavir $(10-15 \mu \mathrm{M})$ or nelfinavir $(5-15 \mu \mathrm{M})$ but not amprenavir 
$(15 \mu \mathrm{M})$, all of which are first generation PI, induced prelamin A accumulation within cells $[36,46]$. Nonotheless, despite the lack of prelamin A detection during amprenavir treatment, a slight increase in the number of dysmorphic nuclei compared to control cells has been described [46].

This disparity was also observed using second generation PIs. Indeed, incubation of cultured cells (48 h [33], 30 days [34]) with at least $10 \mu \mathrm{M}$ lopinavir $[31,32,33]$ or "boosted" lopinavir [32,34] induced the accumulation of lamin A precursor. Atazanavir induced prelamin A accumulation at $20 \mu \mathrm{M}(48 \mathrm{~h}[31,32,33])$, but not at $4 \mu \mathrm{M}$ (passage 2-16, [36]). Moreover, darunavir did not induce prelamin A accumulation $(20 \mu \mathrm{M}, 48 \mathrm{~h}$, [32]).

The differential effects of PIs on lamin A processing could be linked to their different chemical structures and their different affinities for FACE1/ZMPSTE24, which have already been shown for their target HIV protease [47]. Lopinavir and atazanavir are derived from saquinavir (a first generation drug), whereas darunavir is derived from amprenavir [32].

In accordance with previous publications, we observed prelamin A accumulation in cultured dermal fibroblasts treated with lopinavir $(20 \mu \mathrm{M}, 72 \mathrm{~h})$. In our experiments, the ratio of prelamin A to lamin A was lower (ratio $=0.08$ ) compared to that already reported for a similar cell type and technical conditions $($ ratio $=0,23[31])$, which may be explained by the difference in the duration of PI treatment (72 h vs 10 days). Interestingly, this ratio was much higher (ratio $=0.26$ ) when using an anti-lamin A/ $\mathrm{C}$ antibody raised against a different epitope (Figure S2). This emphasised the difference in sensitivity of antibodies for prelamin A. The percentage of mature lamin A was reported as $32 \%$ after lopinavir treatment $(20 \mu \mathrm{M}, 48 \mathrm{~h})$ in another cell type (Saos2 cells) under different experimental conditions (metabolic labelling, immunoprecipitation [33]).

We showed for the first time that prelamin A accumulation was induced in PBMCs cultured in medium containing $20 \mu \mathrm{M}$ or $40 \mu \mathrm{M}$ lopinavir for $24 \mathrm{~h}$. The accumulation of prelamin A increased with PI concentration.

Accumulation of prelamin A induced by PIs has been shown to result from the partial inhibition of ZMSPTE24 [31,32,48]. PI activity was measured via the cleavage of yeast alpha mating factor by mouse Face1/Zmpste24 overexpressed in yeast cells in which the ste 24 gene, which encodes the alpha mating factor protease, was deleted. In these conditions, the half maximal inhibitory concentration (IC50) was different for lopinavir (18.4 $\mu \mathrm{M}$ [31]; $25 \mu \mathrm{M}$ [32]) and atazanavir (150 $\mu \mathrm{M}$ [32]), suggesting that Facel/ Zmpste24 was inhibited to a greater extent by lopinavir than by atazanavir [31,32]. The IC50 of lopinavir for yeast ste24 was $125.6 \mu \mathrm{M}$ [48]. Facel/ZmpSte24 activity remained at over $90 \%$ in the presence of darunavir or amprenavir (up to $150 \mu \mathrm{M}$, [31]).

Farnesylated prelamin A, resulting from inhibition of FACE1/ ZMPSTE24, migrated slightly more rapidly on SDS-PAGE than unfarnesylated prelamin A (Figure S2), as previously shown $[31,32]$. FACE1/ZMPSTE24 inhibition was reported to be reversible [33]. Indeed, only 3 hours after lopinavir wash out, more than $50 \%$ of prelamin A disappeared and the protein was totally undetectable after 7 hours. Nonetheless, nuclear morphology later returned $(7-15 \mathrm{~h})$ to a normal shape and size [33]. Furthermore, in PI exposed cells, a minor prelamin A band appeared and increased with passage number in culture, indicative of cell senescence [34].

\section{No Prelamin A was Detected in PBMCs from Patients being Treated with the $2 \mathrm{NRTI}+1 \mathrm{PI} / \mathrm{r}$ Regimen}

Our patients were considered as clinically stable regarding viral load and GD4+ cell count [38]. The mean duration of
2NRTI+1PI/r treatment was $2.7( \pm 1.3)$ years when patients were recruited at baseline (M0) [38]. Because some patients began their $2 \mathrm{NRTI}+1 \mathrm{PI} / \mathrm{r}$ treatment two years before the M0 sampling, the duration of ART exposure was doubled in these patients in the course of the study. Drug plasma concentrations confirmed patient adherence to treatment and were in accordance with specific pharmacokinetic data previously reported [49]. The large majority of plasma concentrations remained within therapeutic ranges and were stable during follow-up (M0, M12 and M24).

None of the 5 patients being treated with an ART regimen including fosamprenavir displayed prelamin $\mathrm{A}$ in PBMCs. However, fosamprenavir, which is the prodrug of amprenavir, was not expected to induce prelamin A according to in vitro studies $[32,46]$.

Additionally, none of the 5 patients being treated with an ART regimen including atazanavir displayed prelamin $\mathrm{A}$ in PBMCs. These results contrasted with data reported for one patient only [34], in whom the drug plasma concentration was not measured. Nonetheless, higher drug concentrations than those recorded in our patients failed to induce prelamin A in cultured cells [36].

Interestingly, and in contrast with data showing the inhibition of Facel/Zmpste24 by lopinavir in cell culture, none of the 25 patients being treated with an ART regimen including lopinavir presented with alterated prelamin A processing in PBMC. Our observation was not in accordance with a study showing the presence of lopinavir-induced prelamin A in PBMCs from 3 patients whose lopinavir plasma concentration was unknown [34]. Nonetheless, this prelamin A absence could be directly correlated to the discrepancy we observed between the in vitro and in vivo models, and may be explained by the protein binding affinity of PIs and the difference in protein concentration in plasma and cell culture medium.

\section{Several Factors May Explain the Differential Effect of PI on Lamin A Processing in Cultured Cells and in Patient PBMC}

PIs exhibit highly specific and saturable binding to proteins, particularly the plasma proteins serum albumin (SA) and alpha 1 acid glycoprotein (AAG) [50,51,52]. Because more than $90 \%$ of PIs are bound to plasma proteins, only low levels of the drugs remain available to be imported into cells. Nevertheless, the intracellular PIs concentration has not been directly related to protein binding per se [52]. Additionally, it is likely that PIs also bind to intracellular proteins [51]. In treated patients, therapeutic drug monitoring is performed by quantification of the drug concentration in plasma. This procedure is used to monitor the dose suitability, and in some cases can detect patient noncompliance with their treatment schedule. The values obtained are considered to reflect exposure to drugs and correspond to total drug concentration, including both the bound and unbound drug fractions.

In vitro, culture medium supplemented with 10\% FBS (total protein concentration: $4 \mathrm{~g} / \mathrm{L}$ ) contains much less SA and AAG than human plasma (total protein concentration: $60-80 \mathrm{~g} / \mathrm{L}$ ), thus increasing the concentration of unbound PI available to cells [53]. Our results obtained with cells exposed to drugs incubated in plasma (total protein concentration: $60-80 \mathrm{~g} / \mathrm{L}$ ) or in culture medium supplemented with BSA (total protein concentration: $40 \mathrm{~g} / \mathrm{L}$ ) strongly suggested that this phenomenon is of importance. Indeed, both viability and lamin A processing were not altered when PI were incubated in culture medium supplemented with a high concentration of protein. In contrast, cells incubated with PI in culture medium containing a low concentration of proteins exhibited a decrease in cell viability and an accumulation of 
prelamin A. This is in accordance with the inhibitory effect of PI on the prelamin A processing protease, FACE1/ZMPSTE24. Moreover, even if the total PI concentration used in cultured cells is reported to be close to the maximal PI concentration assayed in the plasma of treated patients, few PI molecules are bound to proteins in culture medium, thus increasing the amount of PI available to cells. Therefore, PI concentration exceeds the drug therapeutic range.

Additionally, in cultured cells, the entry of ART drugs into cells is facilitated by the vehicle used (diluted ethanol or DMSO), which likely bypass PI membrane transporters and increase the drug concentration within cells [54].

Indeed, PIs, like other ART drugs, need to enter cells to reach their targets. These mechanisms have long been believed to involve diffusion that depends mainly on the size of the molecules, their lipophilic properties and their binding to proteins [52,53]. However, active influx (organic anion transporters, OAT; organic cation transporters, OCT) [55] and efflux transporters (P-gp or MRP (multidrug resistance associated protein)) [56] play crucial roles in modulating the intracellular concentration of PIs. The expression of some of these transporters has been reported to be cell- or tissue-related (intestine, liver, kidney, blood brain barrier and immune cells $[51,52])$. Interestingly, the PI concentration in CD8+ cells was lower than in CD4+ cells, while the latter expressed less P-gp than the former [52]. To date, comparative studies of the plasma and intracellular concentrations of PIs remain inconsistent, with some studies demonstrating a correlation between these two parameters while others did not $[51,52]$.

Therefore, the influx/efflux dynamics of drugs and their pharmacokinetic characteristics following oral administration, in contrast with the more direct exposure of drugs to cultured cells, are further differences between in vitro and in vivo situations. Indeed, in human patients, PIs and other drugs are constitutively metabolized by p450 cytochrome enzymes, mainly of the CYP3A subfamily in the liver [50,51]. Furthermore, patient PI regimens, but not cell culture medium, contained ritonavir as a CYP3A4 inhibitor, thus leading to potentiation of lopinavir (the main PI in our cohort) [57]. Therefore, the effect of PI on lamin A processing was expected to be emphasised in in vivo compared to in vitro studies.

For all of these reasons, data obtained in cultured cells may be quite different from data recorded in cells from patients. This may explain the absence of prelamin A in PBMCs from PI/r treated patients. Moreover, additional discrepancies between in vitro and in vivo studies have also been described regarding PI mitochondrial toxicity. Whereas an in vitro study highlighted the inhibition of the mitochondrial protease processing by PIs [58], we did not confirm these data in PBMC mitochondria [38].

\section{Could PI be Less Toxic to PBMC than to Other Cells?}

In patients, PI can accumulate to different extents in various tissues and in PBMC $[59,60,61,62]$. Therefore, PI toxicity may be observed in some tissues but not in others.

Ex vivo analyses have previously been performed on adipose tissue from patients being treated with indinavir or nelfinavir regimens who presented with abnormal fat repartition (ART mean duration: 3 years, [36,37]). The patient tissues exhibited prelamin A accumulation as well as an increased percentage of small adipocytes, fibrosis without inflammatory features, and a decrease in the number of blood vessels compared to control tissue samples [37].

A small percentage of patients from our cohort (28\% receiving $2 \mathrm{NRTI}+1 \mathrm{PI} / \mathrm{r}$ as well as $25 \%$ receiving $2 \mathrm{NRTI}+1 \mathrm{NNRTI}$ ) exhibited an abnormal fat distribution. Prelamin A was not detected in PBMCs from these patients.

Interestingly, mice treated with Kaletra (lopinavir/ritonavir; $200 / 50 \mathrm{mg} / \mathrm{kg} /$ day) exhibited no changes in glycemia after a $2-8$ week exposure, although hypertriglyceridemia was observed. Moreover, long-term treatment (8 weeks) markedly remodelled peripheral inguinal adipose deposits but did not alter epididymal fat deposits or brown adipose tissues. These observations were not reproduced with unboosted atazanavir treatment, and only partially mimicked ART-associated lipodystrophic syndromes in humans [63]. Nonetheless, and despite a circulating drug concentration within the therapeutic range expected in patients, mice showed a rapid elimination of ART drugs with a half-life shorter than in humans [63].

Some PI molecules such as indinavir and nelfinavir $[46,64]$ or lopinavir [63] have already been reported to induce altered expression of the adipogenic factor, SREBP1, a transcription factor known to play an important role during adipocyte differentiation. In cultured differentiating adipocytes, indinavir induced SREBP1 sequestration at the nuclear periphery [65]. Inhibition of FACE1/ZMSPTE24 by PIs has already been suggested to contribute to the development of lipodystrophy [33]. Nonetheless, the impact of prelamin A accumulation on adipocyte differentiation remains controversial $[66,67]$.

In cultured cells, impairment of prelamin A processing by PI has been shown to be related to the drugs used and their concentrations, thus reproducing the pathophysiological mechanism of systemic progeroid syndromes. In PBMCs from patients, $\mathrm{PI} / \mathrm{r}$ first line regimens did not result in prelamin A processing abnormalities. Therefore, $\mathrm{PI} / \mathrm{r}$ do not seem to be involved in PBMC lamin A-related aging. We demonstrated that lamin A processing abnormalities were observed in cultured PBMCs from healthy donors only if the protein concentration in the culture medium was low, thus increasing the amount of PI available to enter cells. Nonetheless, the effects of PI/r could be different in other cell types.

\section{Supporting Information}

Figure S1 PBMG incubated with ZoPra, as a positive control for the immunodetection unfarnesylated prelamin A. PBMCs from healthy seronegative subjects were incubated for 24 hours in culture medium containing $60 \mu \mathrm{M}$ ZoPra. Prelamin A was only detected in cells incubated with ZoPra. (A) Western blotting of PBMC protein extracts using a prelamin A-specific antibody and three different lamin A/C-specific antibodies. (B) Immunofluorescence microscopy of PBMC double labelled with antibodies against prelamin A and lamin A. Bar, $20 \mu \mathrm{m}$. (G) Flow cytometry using antibodies against prelamin A and lamin A. (TIF)

Figure S2 Antibody characterization. Fibroblasts were cultured in the presence or absence of either $20 \mu \mathrm{M}$ lopinavir (farnesylated prelamin A positive control) or $60 \mu \mathrm{M}$ ZoPra (unfarnesylated prelamin A positive control) for 72 hours. GAPDH was used as total cellular protein loading control. (A) Western blot comparing the three lamin A/C antibodies used (N18, sc6215; H110, sc20681; Jol2, MAB3211). All antibodies recognized both lamin A and lamin C. Different amounts of farnesylated prelamin A were detected by $\mathrm{N} 18$ and $\mathrm{H} 110$, as shown by the ratio of prelamin A reported to the total prelamin Atlamin A signal. In the same conditions, Jol2 did not detect prelamin A. (B) Western blot comparing the two prelamin A antibodies tested (sc6214, ANT0045). The sc6214 antibody exhibited a higher affinity for both farnesylated and unfarnesylated prelamin A than the 
ANT0045 antibody. (G) Prelamin A, lamin A and lamin C protein domains and antibody epitopes. Lamin A/C N18 (sc6215, green); lamin A/C H110 (sc20681, blue); lamin A/C Jol2 (MAB3211, purple); prelamin A sc6214 (pink); prelamin A ANT0045 (orange). (TIF)

Figure S3 Prelamin A was not detected in PBMC from patients exhibiting the highest plasma concentration of lopinavir. (A) Western blotting of protein extracts prepared from PBMCs isolated from healthy controls and incubated in culture medium containing $60 \mu \mathrm{M}$ ZoPra for 24 hours. Prelamin A was only detected in cells incubated with ZoPra. (B) Western blotting of protein extracts prepared from PBMCs isolated from ANRS EP45 "Aging" patients exhibiting the highest plasma concentration of lopinavir $(16.7-19.0 \mu \mathrm{M})$. The ritonavir concentration is also reported $(0.7-1.8 \mu \mathrm{M})$. No prelamin A was detected.

(TIF)

Protocol S1 The ANRS EP45 "Aging" study. http:// clinicaltrials.gov/, NCT01038999.

(PDF)

Methods S1 Dermal fibroblast culture, protein extraction, immunofluorescence and western blotting procedures.

(DOC)

\section{References}

1. Lin F, Worman HJ (1993) Structural organization of the human gene encoding nuclear lamin A and nuclear lamin C. J Biol Chem 268: 16321-16326.

2. Broers JL, Ramaekers FG, Bonne G, Yaou RB, Hutchison CJ (2006) Nuclear lamins: laminopathies and their role in premature ageing. Physiol Rev 86: 9671008 .

3. Dechat T, Pfleghaar K, Sengupta K, Shimi T, Shumaker DK, et al. (2008) Nuclear lamins: major factors in the structural organization and function of the nucleus and chromatin. Genes Dev 22: 832-853.

4. Prokocimer M, Davidovich M, Nissim-Rafinia M, Wiesel-Motiuk N, Bar DZ, et al. (2009) Nuclear lamins: key regulators of nuclear structure and activities. J Cell Mol Med 13: 1059-1085.

5. Lutz RJ, Trujillo MA, Denham KS, Wenger L, Sinensky M (1992) Nucleoplasmic localization of prelamin A: implications for prenylationdependent lamin A assembly into the nuclear lamina. Proc Natl Acad Sci U S A 89: 3000-3004.

6. Bergo MO, Gavino B, Ross J, Schmidt WK, Hong C, et al. (2002) Zmpste24 deficiency in mice causes spontaneous bone fractures, muscle weakness, and a prelamin A processing defect. Proc Natl Acad Sci U S A 99: 13049-13054.

7. Corrigan DP, Kuszczak D, Rusinol AE, Thewke DP, Hrycyna CA, et al. (2005) Prelamin A endoproteolytic processing in vitro by recombinant Zmpste24. Biochem J 387: 129-138.

8. Pendas AM, Zhou Z, Cadinanos J, Freije JM, Wang J, et al. (2002) Defective prelamin A processing and muscular and adipocyte alterations in Zmpste24 metalloproteinase-deficient mice. Nat Genet 31: 94-99.

9. Andres V, Gonzalez JM (2009) Role of A-type lamins in signaling, transcription, and chromatin organization. Journal of Cell Biology 187: 945-957.

10. Bonne G, Di Barletta MR, Varnous S, Becane HM, Hammouda EH, et al. (1999) Mutations in the gene encoding lamin A/C cause autosomal dominant Emery-Dreifuss muscular dystrophy. Nat Genet 21: 285-288.

11. Fatkin D, MacRae C, Sasaki T, Wolff MR, Porcu M, et al. (1999) Missense mutations in the rod domain of the lamin A/C gene as causes of dilated cardiomyopathy and conduction-system disease. N Engl J Med 341: 1715-1724.

12. Muchir A, Bonne G, van der Kooi AJ, van Meegen M, Baas F, et al. (2000) Identification of mutations in the gene encoding lamins $\mathrm{A} / \mathrm{C}$ in autosomal dominant limb girdle muscular dystrophy with atrioventricular conduction disturbances (LGMD1B). Hum Mol Genet 9: 1453-1459.

13. De Sandre-Giovannoli A, Chaouch M, Kozlov S, Vallat JM, Tazir M, et al. (2002) Homozygous defects in LMNA, encoding lamin A/C nuclear-envelope proteins, cause autosomal recessive axonal neuropathy in human (CharcotMarie-Tooth disorder type 2) and mouse. Am J Hum Genet 70: 726-736.

14. Shackleton S, Lloyd DJ, Jackson SN, Evans R, Niermeijer MF, et al. (2000) LMNA, encoding lamin A/C, is mutated in partial lipodystrophy. Nat Genet 24: $153-156$.

15. Decaudain A, Vantyghem MC, Guerci B, Hecart AC, Auclair M, et al. (2007) New metabolic phenotypes in laminopathies: LMNA mutations in patients with severe metabolic syndrome. Journal of Clinical Endocrinology and Metabolism 92: $4835-4844$.

\section{Acknowledgments}

We thank the patients who participated in this trial and all study investigators and participating centres.

We thank Sandrine Couffin-Cadiergues (ANRS) and Lucie Marchand (ANRS) for their study follow up.

We particularly thank Caroline Debreux (Clinical Research Assistant, Marseille), Gilda Soprano (Clinical Research Assistant, Montpellier) and Marie-Ange Serini (Clinical Research Assistant, Nice) for their excellent assistance in study coordination, and Samira Miloudi (Clinical Research Assistant, Marseille) for her clinical data quality control.

We wish to acknowledge Olivier Jean for his expertise regarding the flow cytometry experiments as well as Claire Navarro, Joëlle Fiteni, Corinne Derrien, Nathalie Boitano, Chantal Paolasso, Karine Bertaux, Cécile Mouradian and Hélène Riera for their help and continuous support.

We thank Anthony Lodge (APL Scientific) for English editing of the manuscript.

\section{Author Contributions}

Conceived and designed the experiments: SP PG PR. Performed the experiments: SP JC. Analyzed the data: SP JC PC PR AR-S C. Stretti EK NL C. Solas CN-B BL. Contributed reagents/materials/analysis tools: CN-B C. Solas BL. Wrote the paper: SP PC PR C. Solas. ANRS EP45 "Aging" study design: IP-M JR PD JM PR PC. Management of the recruitement of HIV patients: OF. Management of the recruitement of control subjects: JM. Study quality control: JM. Virological analysis: CT. Antiretroviral plasma assays: C. Solas BL.

16. Dutour A, Roll P, Gaborit B, Courrier S, Alessi MC, et al. (2011) High prevalence of laminopathies among patients with metabolic syndrome. Hum Mol Genet 20: 3779-3786.

17. Eriksson M, Brown WT, Gordon LB, Glynn MW, Singer J, et al. (2003) Recurrent de novo point mutations in lamin A cause Hutchinson-Gilford progeria syndrome. Nature 423: 293-298.

18. Navarro CL, Gau P, Levy N (2006) Molecular bases of progeroid syndromes. Hum Mol Genet 15 Suppl 2: R151-161.

19. Hennekam RC (2006) Hutchinson-Gilford progeria syndrome: review of the phenotype. Am J Med Genet A 140: 2603-2624

20. Navarro CL, De Sandre-Giovannoli A, Bernard R, Boccaccio I, Boyer A, et al. (2004) Lamin A and ZMPSTE24 (FACE-1) defects cause nuclear disorganization and identify restrictive dermopathy as a lethal neonatal laminopathy. Hum Mol Genet 13: 2493-2503.

21. Navarro CL, Cadinanos J, De Sandre-Giovannoli A, Bernard R, Courrier S, et al. (2005) Loss of ZMPSTE24 (FACE-1) causes autosomal recessive restrictive dermopathy and accumulation of Lamin A precursors. Hum Mol Genet 14: 1503-1513.

22. Scaffidi P, Misteli T (2006) Lamin A-dependent nuclear defects in human aging. Science 312: 1059-1063.

23. Ragnauth CD, Warren DT, Liu Y, McNair R, Tajsic T, et al. (2010) Prelamin A acts to accelerate smooth muscle cell senescence and is a novel biomarker of human vascular aging. Circulation 121: 2200-2210.

24. Deeks SG, Phillips AN (2009) HIV infection, antiretroviral treatment, ageing, and non-AIDS related morbidity. Bmj 338: a3172.

25. Deeks SG (2011) HIV infection, inflammation, immunosenescence, and aging. Annu Rev Med 62: 141-155.

26. Garg A (2011) Clinical review\#: Lipodystrophies: genetic and acquired body fat disorders. J Clin Endocrinol Metab 96: 3313-3325.

27. Guaraldi G, Orlando G, Zona S, Menozzi M, Carli F, et al. (2011) Premature age-related comorbidities among HIV-infected persons compared with the general population. Clin Infect Dis 53: 1120-1126.

28. Scott ES, O'Hare P (2001) Fate of the inner nuclear membrane protein lamin B receptor and nuclear lamins in herpes simplex virus type 1 infection. J Virol 75 : 8818-8830.

29. Muranyi W, Haas J, Wagner M, Krohne G, Koszinowski UH (2002) Cytomegalovirus recruitment of cellular kinases to dissolve the nuclear lamina. Science 297: 854-857.

30. de Noronha CM, Sherman MP, Lin HW, Cavrois MV, Moir RD, et al. (2001) Dynamic disruptions in nuclear envelope architecture and integrity induced by HIV-1 Vpr. Science 294: 1105-1108.

31. Coffinier C, Hudon SE, Farber EA, Chang SY, Hrycyna CA, et al. (2007) HIV protease inhibitors block the zinc metalloproteinase ZMPSTE24 and lead to an accumulation of prelamin A in cells. Proc Natl Acad Sci U S A 104: 1343213437.

32. Coffinier C, Hudon SE, Lee R, Farber EA, Nobumori G, et al. (2008) A potent HIV protease inhibitor, darunavir, does not inhibit ZMPSTE24 or lead to an 
accumulation of farnesyl-prelamin A in cells. Journal of Biological Chemistry 283: 9797-9804.

33. Liu Q, Kim DI, Syme J, LuValle P, Burke B, et al. (2010) Dynamics of lamin-A processing following precursor accumulation. PLoS ONE 5: e10874.

34. Lefevre C, Auclair M, Boccara F, Bastard JP, Capeau J, et al. (2010) Premature senescence of vascular cells is induced by HIV protease inhibitors: implication of prelamin A and reversion by statin. Arteriosclerosis, Thrombosis, and Vascular Biology 30: 2611-2620.

35. Miranda M, Chacon MR, Vidal F, Megia A, Richart C, et al. (2007) LMNA messenger RNA expression in highly active antiretroviral therapy-treated HIVpositive patients. J Acquir Immune Defic Syndr 46: 384-389.

36. Caron M, Auclair M, Donadille B, Bereziat V, Guerci B, et al. (2007) Human lipodystrophies linked to mutations in A-type lamins and to HIV protease inhibitor therapy are both associated with prelamin A accumulation, oxidative stress and premature cellular senescence. Cell Death Differ 14: 1759-1767.

37. Bereziat V, Cervera P, Le Dour G, Verpont MC, Dumont S, et al. (2011) LMNA mutations induce a non-inflammatory fibrosis and a brown fat-like dystrophy of enlarged cervical adipose tissue. Am J Pathol 179: 2443-2453.

38. Perrin S, Cremer J, Roll P, Faucher O, Menard A, et al. (2012) HIV-1 Infection and First Line ART Induced Differential Responses in Mitochondria from Blood Lymphocytes and Monocytes: The ANRS EP45 "Aging" Study. PLoS One 7: e41129.

39. Justesen US, Pedersen C, Klitgaard NA (2003) Simultaneous quantitative determination of the HIV protease inhibitors indinavir, amprenavir, ritonavir, lopinavir, saquinavir, nelfinavir and the nelfinavir active metabolite M8 in plasma by liquid chromatography. J Chromatogr B Analyt Technol Biomed Life Sci 783: 491-500.

40. Colombo S, Guignard N, Marzolini C, Telenti A, Biollaz J, et al. (2004) Determination of the new HIV-protease inhibitor atazanavir by liquid chromatography after solid-phase extraction. J Chromatogr B Analyt Technol Biomed Life Sci 810: 25-34.

41. Marzolini C, Beguin A, Telenti A, Schreyer A, Buclin T, et al. (2002) Determination of lopinavir and nevirapine by high-performance liquid chromatography after solid-phase extraction: application for the assessment of their transplacental passage at delivery. J Chromatogr B Analyt Technol Biomed Life Sci 774: 127-140.

42. Marsh KC, Eiden E, McDonald E (1997) Determination of ritonavir, a new HIV protease inhibitor, in biological samples using reversed-phase highperformance liquid chromatography. J Chromatogr B Biomed Sci Appl 704: 307-313.

43. van Heeswijk RP, Hoetelmans RM, Harms R, Meenhorst PL, Mulder JW, et al. (1998) Simultaneous quantitative determination of the HIV protease inhibitors amprenavir, indinavir, nelfinavir, ritonavir and saquinavir in human plasma by ion-pair high-performance liquid chromatography with ultraviolet detection. J Chromatogr B Biomed Sci Appl 719: 159-168.

44. Quaranta S, Woloch C, Paccou A, Giocanti M, Solas C, et al. (2009) Validation of an electrospray ionization LC-MS/MS method for quantitative analysis of raltegravir, etravirine, and 9 other antiretroviral agents in human plasma samples. Ther Drug Monit 31: 695-702.

45. Varela I, Pereira S, Ugalde AP, Navarro CL, Suarez MF, et al. (2008) Combined treatment with statins and aminobisphosphonates extends longevity in a mouse model of human premature aging. Nat Med 14: 767-772.

46. Caron M, Auclair M, Sterlingot H, Kornprobst M, Capeau J (2003) Some HIV protease inhibitors alter lamin A/C maturation and stability, SREBP-1 nuclear localization and adipocyte differentiation. Aids 17: 2437-2444.

47. Ghosh AK, Chapsal BD, Weber IT, Mitsuya H (2008) Design of HIV protease inhibitors targeting protein backbone: an effective strategy for combating drug resistance. Acc Chem Res 41: 78-86.

48. Hudon SE, Coffinier C, Michaelis S, Fong LG, Young SG, et al. (2008) HIVprotease inhibitors block the enzymatic activity of purified Ste24p. Biochemical and Biophysical Research Communications 374: 365-368.
49. Yeni (2010) Prise en charge médicale des personnes infectées par le VIH. ISBN : 978-2-11-008038-7. Available: http://www.sante.gouv.fr/rapport-2010-sur-laprise-en-charge-medicale-des-personnes-infectees-par-le-vih-sous-la-directiondu-pr-patrick-yeni.html. Accessed: 2012 Jun 21.

50. Arab-Alameddine M, Decosterd LA, Buclin T, Telenti A, Csajka C (2011) Antiretroviral drug toxicity in relation to pharmacokinetics, metabolic profile and pharmacogenetics. Expert Opin Drug Metab Toxicol.

51. Bazzoli C, Jullien V, Le Tiec C, Rey E, Mentre F, et al. (2010) Intracellular Pharmacokinetics of Antiretroviral Drugs in HIV-Infected Patients, and their Correlation with Drug Action. Clin Pharmacokinet 49: 17-45.

52. Ford J, Khoo SH, Back DJ (2004) The intracellular pharmacology of antiretroviral protease inhibitors. J Antimicrob Chemother 54: 982-990.

53. Boffito M, Back DJ, Blaschke TF, Rowland M, Bertz RJ, et al. (2003) Protein binding in antiretroviral therapies. AIDS Res Hum Retroviruses 19: 825-835.

54. Janneh O, Hartkoorn RC, Jones E, Owen A, Ward SA, et al. (2008) Cultured CD4T cells and primary human lymphocytes express hOATPs: intracellular accumulation of saquinavir and lopinavir. Br J Pharmacol 155: 875-883.

55. Hartkoorn RC, Kwan WS, Shallcross V, Chaikan A, Liptrott N, et al. (2010) HIV protease inhibitors are substrates for OATP1A2, OATP1B1 and OATP1B3 and lopinavir plasma concentrations are influenced by SLCO1B1 polymorphisms. Pharmacogenet Genomics 20: 112-120.

56. Turriziani O, Gianotti N, Falasca F, Boni A, Vestri AR, et al. (2008) Expression levels of MDR1, MRP1, MRP4, and MRP5 in peripheral blood mononuclear cells from HIV infected patients failing antiretroviral therapy. J Med Virol 80: $766-771$.

57. Oldfield V, Plosker GL (2006) Lopinavir/ritonavir: a review of its use in the management of HIV infection. Drugs 66: 1275-1299.

58. Mukhopadhyay A, Wei B, Zullo SJ, Wood LV, Weiner H (2002) In vitro evidence of inhibition of mitochondrial protease processing by HIV-1 protease inhibitors in yeast: a possible contribution to lipodystrophy syndrome. Mitochondrion 1: 511-518.

59. Lafeuillade A, Solas G, Halfon P, Chadapaud S, Hittinger G, et al. (2002) Differences in the detection of three HIV-1 protease inhibitors in non-blood compartments: clinical correlations. HIV Clin Trials 3: 27-35.

60. Di Mascio M, Srinivasula S, Bhattacharjee A, Cheng L, Martiniova L, et al. (2009) Antiretroviral Tissue Kinetics: In Vivo Imaging Using Positron Emission Tomography. Antimicrob Agents Chemother 53: 4089-4095.

61. Cohen J (2011) HIV/AIDS research. Tissue says blood is misleading, confusing HIV cure efforts. Science 334: 1614.

62. Patterson KB, Prince HA, Kraft E, Jenkins AJ, Shaheen NJ, et al. (2011) Penetration of Tenofovir and Emtricitabine in Mucosal Tissues: Implications for Prevention of HIV-1 Transmission. Science Translational Medicine 3: 112re114-112re114.

63. Prot M, Heripret L, Cardot-Leccia N, Perrin C, Aouadi M, et al. (2006) Longterm treatment with lopinavir-ritonavir induces a reduction in peripheral adipose depots in mice. Antimicrob Agents Chemother 50: 3998-4004.

64. Bastard JP, Caron M, Vidal H, Jan V, Auclair M, et al. (2002) Association between altered expression of adipogenic factor SREBP1 in lipoatrophic adipose tissue from HIV-1-infected patients and abnormal adipocyte differentiation and insulin resistance. Lancet 359: 1026-1031.

65. Caron M, Auclair M, Vigouroux C, Glorian M, Forest C, et al. (2001) The HIV protease inhibitor indinavir impairs sterol regulatory element-binding protein-1 intranuclear localization, inhibits preadipocyte differentiation, and induces insulin resistance. Diabetes 50: 1378-1388.

66. Kudlow BA, Jameson SA, Kennedy BK (2005) HIV protease inhibitors block adipocyte differentiation independently of lamin A/C. Aids 19: 1565-1573.

67. Boguslavsky RL, Stewart CL, Worman HJ (2006) Nuclear lamin A inhibits adipocyte differentiation: implications for Dunnigan-type familial partial lipodystrophy. Hum Mol Genet 15: 653-663. 